\title{
Distribution and movement of domestic rainbow trout, Oncorhynchus mykiss, during pulsed flows in the South Fork American River, California
}

\author{
Sarah A. Cocherell • Gardner J. Jones • Javier B. Miranda • Dennis E. Cocherell • \\ Joseph J. Cech Jr. • Lisa C. Thompson • A. Peter Klimley
}

Received: 1 October 2009 / Accepted: 29 July 2010/Published online: 11 August 2010

(C) The Author(s) 2010. This article is published with open access at Springerlink.com

\begin{abstract}
We tracked the movements of ten small $(\mathrm{SL}=25.5-31.0 \mathrm{~cm})$ and ten large $(\mathrm{SL}=32.0-38.5 \mathrm{~cm})$ radio-tagged domestic rainbow trout (Oncorhynchus mykiss) in response to frequent pulsed releases of water in the South Fork American River (California) from July to October 2005. In week one all the small trout moved less than $1 \mathrm{~km}$ upstream or downstream of their release sites. Four small trout moved 1-3 km upstream or downstream of their release sites in the following 8 weeks. Seven out of ten large trout moved downstream after their release. In subsequent weeks most large trout showed smaller upstream and downstream movements, and were observed between $1 \mathrm{~km}$ upstream and $8 \mathrm{~km}$ downstream of their release sites. Our results suggest that domestic rainbow trout with SL $>25 \mathrm{~cm}$ are not forced downstream by daily pulsed flow increases from 5 to over $40 \mathrm{~m}^{3} \mathrm{~s}^{-1}$.
\end{abstract}

Keywords Distribution · Movement · Pulsed flows · Radio telemetry · Rainbow trout Oncorhynchus mykiss

S. A. Cocherell • D. E. Cocherell • J. J. Cech Jr. •

L. C. Thompson $(\bowtie) \cdot$ A. P. Klimley

Wildlife, Fish, \& Conservation Biology Department,

University of California Davis,

1 Shields Avenue,

Davis, CA 95616-8751, USA

e-mail: 1cthompson@ucdavis.edu

G. J. Jones · J. B. Miranda

California Department of Water Resources,

P.O. Box 942836, Sacramento, CA 94236-0001, USA

\section{Introduction}

This is one of a set of papers that, collectively, use an interdisciplinary approach, including telemetry, physiology, behavior, and experimental biology, in both laboratory and field settings, to study the response of fish to pulsed flows (Klimley et al. 2005, 2007). This approach is consistent with recent suggestions that interdisciplinary research is essential to address complex fish biology processes such as movement and migration, and that telemetry is a tool that allows integration across disciplines and between the laboratory and field (Cooke et al. 2008). Our studies were prompted by the need to provide improved information on fish biology in light of the re-licensing efforts underway and anticipated for numerous California dams (Klimley et al 2005, 2007).

Human-controlled flows are common in rivers. Pulsed flows are relatively rapid increases in flows followed by relatively rapid decreases in these flows, with flow fluctuations lasting minutes, hours, or days (Hunter 1992). Reasons for pulsed flows include: (1) generating electricity, (2) flushing streambeds, (3) facilitating human recreation, (4) providing additional water for downstream diversion for irrigation, and (5) preventing reservoirs from flooding. The most common rationale for controlling the flows of rivers is the production of electrical energy. Pulsed flows provide additional electrical energy during hot summer days when electrical loads from air conditioners are highest (Hunter 1992). Flushing flows may be brief and 
infrequent, but also sufficiently large that they move silt and sand downstream from the stream bed where they have settled due to slow water flow (Reiser et al. 1989). Recreational flows are water releases made to accommodate activities such as rafting and kayaking. It is well recognized that sudden flow fluctuations may cause stranding of juvenile salmonids in shallow side channels (Maciolek and Needham 1952; Hvidsten 1985) and on river bars (Bradford et al. 1995), and it is now common for dam operators to address this problem by gradually ramping flows up and down during pulses (e.g., PGE 2005a), thus allowing pulsed flow regimes to continue. Although pulsed water releases provide obvious benefits to humans, the cumulative effects of repeated and unseasonal flow pulses on aquatic communities are relatively unknown. Native Californian fish species have evolved with seasonal fluctuations (Moyle 2002), but the increased frequency of pulses (e.g., for electricity generation) and the late-summer timing (for recreational purposes such as whitewater rafting) represent significant deviations from the natural hydrograph.

These pulsed flows may impact the behavior of resident or migratory fish, particularly juvenile salmonids, by forcing them downstream (McCrimmon 1954; Erman and Leidy 1975; Ottaway and Clarke 1981; Ottaway and Forrest 1983; Heggenes and Traaen 1988; Crisp 1991; Crisp and Hurley 1991; Pearsons et al. 1992). This may result in increased mortality, decreased growth, or decreased reproduction. In contrast, the longitudinal displacement of larger fish seems less likely due to their increased swimming performance, compared with smaller fishes (Webb 1971), unless there are velocity refugia that are more accessible to smaller-sized fish. Field studies have found no consistent effect of sudden, extreme peaking flows on area use or movements by adult trout and salmon (Bunt et al. 1999; Gido et al. 2000; Scruton et al. 2005; Heggenes et al. 2007).

In the current study our objective was to identify the longitudinal distribution of rainbow trout released into the South Fork American River, California under the influence of repeated pulsed flows. We were particularly interested in whether trout would be displaced downstream rapidly (i.e., over a period of days to weeks) by repeated pulses. The unpredictable flow releases in this system, which often occurred overnight, precluded our tracking the location of each fish before, during, and after each pulse release. However, given the prevalence of pulsed flow releases in California, management agencies have expressed interest in the general movement behavior of fish under this type of hydrological regime. For example, hatchery rainbow trout are stocked into the South Fork American River for sport fishing, but it is not known whether these fish remain in the river until they are caught by anglers, or whether they are rapidly washed downstream into Folsom Reservoir.

\section{Study area}

The hydrological regime of the South Fork American River is characterized by strong pulsed flows (Fig. 1).
Fig. 1 Water discharge from Chili Bar Dam into the South Fork American River during 13 weeks from July to October 2005 (data from Pacific Gas and Electric). Arrow indicates the date when pulsed flows started. Note: Flow values were sometimes missing for periods of hours to days, resulting in the jagged (pixilated) appearance of the data line

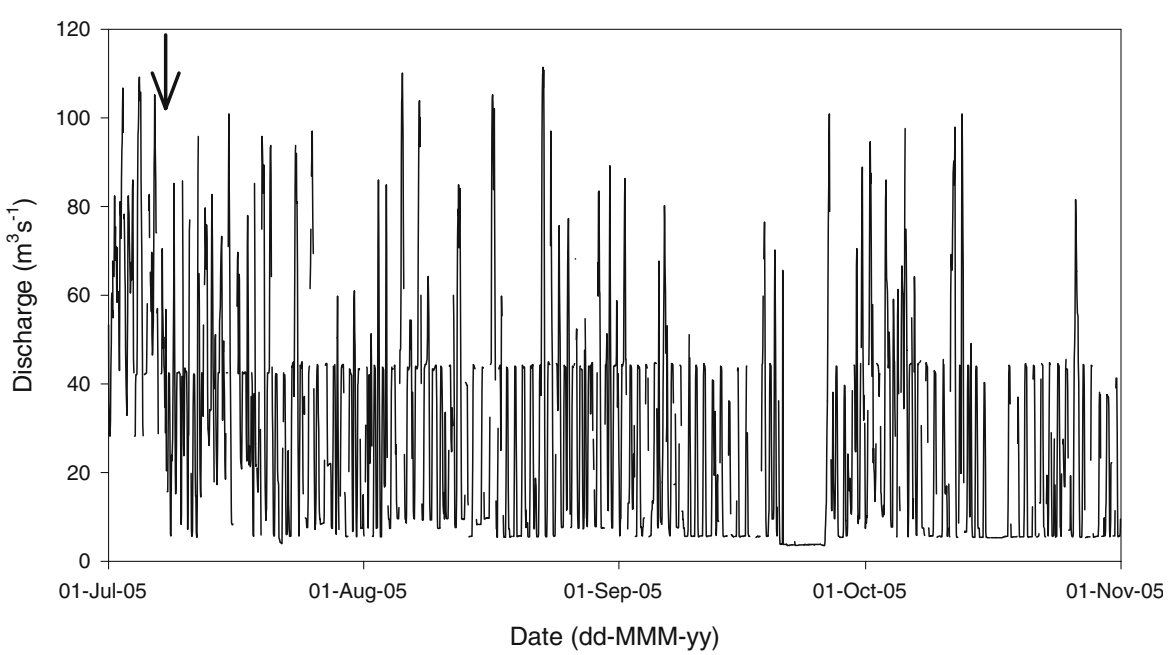


From July to September water is released in pulses from Chili Bar Dam during the day, for recreational flows, and sometimes during the night, as part of hydroelectric power generation by the chain of dams along the South Fork American River. The baseflow in the $30 \mathrm{~km}$ Chili Bar reach is typically $5 \mathrm{~m}^{3} \mathrm{~s}^{-1}$ and recreational pulses are usually $40 \mathrm{~m}^{3} \mathrm{~s}^{-1}$. Pulses are ramped, last about $4-5 \mathrm{~h}$, and move through the reach to Folsom Reservoir in about $6 \mathrm{~h}$ (PGE 2005a). The mean daily temperature of water released from Chili Bar Dam ranges from $11^{\circ} \mathrm{C}$ to $18^{\circ} \mathrm{C}$ during summer (PGE 2005b). The water warms during passage along the reach, with the daily mean ranging from $13^{\circ} \mathrm{C}$ to $21.7^{\circ} \mathrm{C}$ near the end of the reach. At the sites at which our fish were released the mean daily water temperature typically does not exceed $20^{\circ} \mathrm{C}$ (FERC 2008). The daily temperature range at a given point along the reach is approximately $3^{\circ} \mathrm{C}$, with midday warming offset by the pulse of cooler water (PGE 2005a).

\section{Methods}

The rainbow trout used in the study were raised in the California Department of Fish and Game's American River Trout Hatchery, which is located on the American River downstream of Nimbus Dam. We obtained two groups of rainbow trout: one in midFebruary 2005, and the other in late June 2005. The two groups of trout were from two different spawning events. The mid-February fish (June release) were born in November 2004 and the late-June fish (August release) were born in February 2005. Once they were transferred to the University of California, Davis, Center for Aquatic Biology and Aquaculture (CABA) both groups of fish were raised at $18^{\circ} \mathrm{C}$ (the ambient temperature of the well water). The fish we obtained in February had 4 months to grow at this temperature, while the second group had only 2 months. Thus, the first release group was both 3 months older, and had more time at $18^{\circ} \mathrm{C}$, resulting in a larger average size prior to release (Table 1).

We used hatchery, instead of wild, rainbow trout in our studies because the sections of the Chili Bar reach in which we worked had particularly low densities of catchable trout (rainbow trout and brown trout $\geq 150 \mathrm{~mm} \mathrm{TL}$ ) (SMUD and PGE 2005). It was of value to identify the effect of pulsed flows on hatchery-reared trout because they are periodically released into the South Fork American River by the California Department of Fish and Game to provide recreational fishing opportunities.

We placed radio transmitters of two sizes in the peritoneum of large and small trout. The individually coded transmitter (Lotek, NTC-6-2) implanted in large trout was cylindrical, $30.1 \mathrm{~mm}$ long with a diameter of $9.1 \mathrm{~mm}$, and weighed $4.5 \mathrm{~g}$ in air. It emitted a pulse burst every $5 \mathrm{~s}$ of a radio frequency of $147 \mathrm{MHz}$ and had a life span of 124 days. The coded transmitter (Lotek, NTC-4-2L) placed in small trout was also cylindrical, $18.3 \mathrm{~mm}$ long with a diameter of $8.3 \mathrm{~mm}$, weighed $2.1 \mathrm{~g}$ in air. This tag emitted a pulse burst every $5 \mathrm{~s}$ of $149 \mathrm{MHz}$ and had a life span of 85 days. The tags' masses were $<2 \%$ of body masses, and thus were unlikely to hinder the swimming movements of the trout (Jepsen et al. 2002).

The fish were anesthetized with a solution of sodium bicarbonate and glacial acetic acid (Peake 1998). Each fish was anesthetized to Stage 4 anesthesia; characterized by loss of orientation and slowing of opercular movement. The fish was then removed from the anesthetic solution, weighed, and measured for its standard length (SL). A health index was calculated for each fish based on its external body condition, using a modification of the injury index developed by Swanson et al. (2004). Damage was rated from 1 (no damage) to 5 (severe damage) for the following 11 physical features: eyes, operculum, fins (anal, caudal, dorsal, pectoral, pelvic), scales, abrasions, fin blood, and presence of fungus. A fish in ideal condition would score 11, while the worst possible score was 55 .

The fish was then placed supinely on a surgical table and the anesthetic solution was passed continuously over the gills with tubing connected to a recirculating pump. A $1-2 \mathrm{~cm}$ long incision was made between the ribs and the pelvic girdle, $1-2 \mathrm{~cm}$ lateral to the midline. To avoid damaging internal organs, a plastic-sheathed, 16-gauge needle-tipped catheter was used to puncture the body wall, creating an exit point for the whip antenna. After removing the needle, the whip antenna was threaded into the peritoneum through the incision and out through the plastic catheter sheath. The tag was then gently pushed through the incision into the fish's peritoneum. Three to four absorbable sutures (Vicryl ${ }^{\mathrm{TM}}, 3 / 0$ ) closed the incision, and each suture was dotted with liquid topical tissue adhesive (Nexaband ${ }^{\mathrm{TM}}$ ) to secure the knots. 
Table 1 Standard length (SL) and weight of radio-tagged rainbow trout released in the South Fork American River. The large trout (RT1-10) were released in the river on 7 July 2006 and tracked for a period of 13 weeks from 8 July to 29
September 2005, including 11 August. The small trout (RT1120) were released in the river on 12 August 2005 and tracked for a period of 9 weeks from 13 August to 13 October 2005

Fish SL (cm) Weight (g) Telemetry Error (m) mean \pm se Dates Radio-Tagged Fish Tracked

\begin{tabular}{|c|c|c|c|c|c|c|c|c|c|c|c|c|c|c|c|c|c|c|}
\hline & & & & \\
\hline & & & & \multicolumn{4}{|c|}{ July } & \multicolumn{4}{|c|}{ August } & \multicolumn{5}{|c|}{ September } & \multicolumn{2}{|c|}{ October } \\
\hline & & & & 8 & 14 & 21 & 28 & 4 & $11 / 13$ & 18 & 25 & 1 & 8 & 15 & 22 & 29 & 6 & 13 \\
\hline RT1 & 38.5 & 1242 & $15.0 \pm 3.1$ & + & - & 0 & 0 & + & - & घ & - & - & - & - & - & . & & \\
\hline RT2 & 35.0 & 970 & $14.5 \pm 2.9$ & - & - & + & 0 & 0 & 0 & - & - & - & - & - & - & - & & \\
\hline RT3 & 34.0 & 909 & $15.1 \pm 2.8$ & घ & - & + & + & - & 0 & 0 & + & + & 0 & 0 & 0 & 0 & & \\
\hline RT4 & 36.0 & 1020 & $15.4 \pm 3.3$ & a & - & - & + & 0 & + & - & 0 & घ & - & a & घ & घ & & \\
\hline RT5 & 32.0 & 864 & $15.9 \pm 2.8$ & घ & 0 & - & घ & - & 0 & 0 & 0 & 0 & + & + & 0 & + & & \\
\hline RT6 & 36.0 & 1050 & $20.3 \pm 3.7$ & घ & 0 & + & घ & - & 0 & 0 & $X$ & & & & & & & \\
\hline RT7 & 38.0 & 1205 & $12.6 \pm 1.9$ & - & - & + & a & + & - & 0 & 0 & 0 & 0 & 0 & - & - & & \\
\hline RT8 & 34.0 & 1115 & $18.3 \pm 4.7$ & 口 & - & - & - & - & + & घ & घ & घ & - & घ & घ & घ & & \\
\hline RT9 & 36.0 & 1235 & $20.8 \pm 2.7$ & - & - & 0 & - & 0 & + & - & 0 & + & 0 & 0 & 0 & - & & \\
\hline RT10 & 34.0 & 980 & $20.9 \pm 5.0$ & - & - & 0 & - & - & 0 & + & 0 & 0 & 0 & 0 & घ & - & & \\
\hline RT11 & 28.0 & 365 & $11.9 \pm 2.9$ & & & & & & + & + & + & - & + & $X$ & & & & \\
\hline RT12 & 27.0 & 341 & $10.2 \pm 1.6$ & & & & & & + & + & - & + & 0 & + & - & + & - & + \\
\hline RT13 & 31.0 & 500 & $10.5 \pm 1.9$ & & & & & & + & - & - & 0 & + & + & 0 & 0 & - & + \\
\hline RT14 & 29.0 & 459 & $11.4 \pm 1.7$ & & & & & & - & 0 & 0 & 0 & 0 & 0 & 0 & - & $\mathrm{X}$ & \\
\hline RT15 & 28.0 & 374 & $10.0 \pm 1.7$ & & & & & & - & 0 & 0 & 0 & 0 & - & 0 & 0 & - & 0 \\
\hline RT16 & 27.5 & 335 & $12.8 \pm 2.3$ & & & & & & 0 & - & + & - & + & + & घ & + & - & + \\
\hline RT17 & 30.5 & 520 & $15.0 \pm 1.8$ & & & & & & - & - & + & - & + & - & 0 & - & + & 0 \\
\hline RT18 & 30.0 & 474 & $12.5 \pm 1.3$ & & & & & & + & 0 & 0 & - & 0 & - & 0 & + & 0 & - \\
\hline RT19 & 25.5 & 242 & $10.5 \pm 1.9$ & & & & & & - & + & 0 & - & + & + & 0 & - & - & 0 \\
\hline RT20 & 31.0 & 479 & $16.0 \pm 3.8$ & & & & & & - & + & - & + & - & + & 0 & + & - & + \\
\hline
\end{tabular}

Symbols under each date indicate the location of each fish relative to its position the previous week: same location $(0)$, upstream $(+)$, downstream (-), or not located ( $\mathbf{-})$. Upstream or downstream movement is noted only where this movement was in excess of the additive telemetry error for a given fish for the previous and current week. Three fish were captured by anglers, killed, and their tags returned, indicated by an $\mathrm{X}$

We placed radio transmitters in 20 rainbow trout (Table 1). There was no mortality or illness following surgery. Ten large individuals (RT1-RT10), with SL from 32.0 to $38.5 \mathrm{~cm}$, were tagged on 24 and 30 June 2005 and permitted to recover from the surgery at CABA for 1-2 weeks. On 7 July 2005, five large fish were released into the river at Site $1,16.1 \mathrm{~km}$ upstream (Rkm) of Folsom Reservoir, and five were released at Site 2, $12.9 \mathrm{Rkm}$ from the reservoir. Ten small individuals (RT11-RT20), with SL from 25.5 to $31.0 \mathrm{~cm}$, were tagged on 4 August 2005 and allowed to recover for a week. On 12 August 2005, five small fish were released at Site 1, and five were released at Site 2 . The tagged trout were released at two different sites to avoid introducing fish in high densities that might displace fish already present, and to minimize tag-code collisions while tracking. To facilitate locating the trout within the river we related transmitter signal power to distance for trout held temporarily in an enclosure in the river at the release sites.

The trout were located once weekly using a radio receiver and antenna, as we moved down the river in an inflatable raft during a pulsed flow. This sampling frequency was chosen to allow us to detect any net weekly displacement upstream or downstream that might occur in the presence of repeated pulsed releases. For safety reasons, track- 
ing was conducted during daylight only. We recorded at least two sets of bearings from points on the riverbank for each fish, one further upstream or downstream from the other, and from the opposite side of the river, when possible. Fish location was estimated by triangulation of lines based on recorded maximum-signal-strength bearings. Fish locations were also based on transmitter signal strengths recorded as we rafted down the river. We recorded the trout's geographical coordinates using the receiver, the signal strength of the transmitter, the receiver's gain while observing the habitat of the trout (rapid, run, pool), and its location (river right, left, or middle) when the signal power of the transmitter was above 160 units. Tag calibration regressions were combined with the spatial error displayed on a GPS receiver (Garmin GPSmap 76s) to calculate the amount of error associated with each GPS-derived position, termed the telemetry error. Water temperature was measured from the raft during morning and evening periods to corroborate temperature patterns observed along the reach between Chili Bar Dam and Folsom Reservoir in prior studies.

We performed a mixed-model analysis of fish movement, using the ranked distance moved per week as the dependent variable (SAS for Windows Version $9.1^{\circledR}$, proc mixed), using restricted maximum likelihood (REML, default), and including tests for the variance components (covtest option). The distribution of the data precluded analyzing the data using linear model theory. Fish identification number was a subject effect. Weekly distance moved was a repeated measure over time. We considered 11 fixed main effects: size, weight, health index, release location, week, habitat type, lateral location in the river, mean weekly daytime peak flow, mean weekly nighttime peak flow, mean weekly flow, and weekly flow range.

We did not include water temperature as a predictive variable because we did not know at which locations fish might have been between the weekly times that we located them, thus we did not know what temperatures fish had experienced. Furthermore, daily temperatures fluctuated over a relatively small range, compared with the large flow fluctuations that occurred once or more each day. Temperatures at the release sites were always well below the lethal limit for rainbow trout (approximately $24^{\circ} \mathrm{C}$; Beschta et al. 1987), and frequently in the optimal range for rearing.

\section{Results}

During this study pulsed flows were usually discharged daily from Chili Bar Dam for approximately 4 hours, 09:00-13:00, for recreation, increasing the flow of water in the South Fork American River from $5 \mathrm{~m}^{3} \mathrm{~s}^{-1}$ to $40 \mathrm{~m}^{3} \mathrm{~s}^{-1}$ (Fig. 1). This pattern is absent during the first week of July because of snowmelt flows that exceeded the minimum recreational releases. In addition to the recreational releases, flows ranging from 50 to $110 \mathrm{~m}^{3} \mathrm{~s}^{-1}$ were released, generally overnight, to manage water for hydroelectric power generation. There was greater variability between the baseline and maximum flows during the nighttime releases than during the day-the baseline varied from the absence of a release to $40 \mathrm{~m}^{3} \mathrm{~s}^{-1}$ and maximum flows varied from the absence of a pulsed flow to a release of $110 \mathrm{~m}^{3} \mathrm{~s}^{-1}$.

Water temperatures fell within the range observed in previous studies (PGE 2005a, b; FERC 2008). The afternoon temperature of the river, measured from the tracking boat, was between $16^{\circ} \mathrm{C}$ and $19.4^{\circ} \mathrm{C}$ in early July, during the week after the ten large fish were released, and was still over $16^{\circ} \mathrm{C}$ when the small fish were released in mid-August. Afternoon temperatures decreased to less than $15^{\circ} \mathrm{C}$ by mid October. The daily variation in temperature as we moved downstream was $1.0^{\circ} \mathrm{C}$ to $2.5^{\circ} \mathrm{C}$ from upstream sites in the morning to downstream sites in the afternoon.

The signal strength of transmitters in two small trout (NTC-4-2L tag) was described by the following relationship: Signal power $=-3.34$ Distance $(\mathrm{m})+$ $226.11\left(r^{2}=0.83, n=36\right)$. For one large trout (NTC-6$2 \mathrm{tag})$, with receiver gain set at 60 , the relationship was: Signal power $=-2.69$ Distance $(\mathrm{m})+233.75\left(r^{2}=0.85\right.$, $n=8$ ). The range of the transmitter's positional error was: large tags, 4 to $49 \mathrm{~m}$; small tags, 4 to $36 \mathrm{~m}$ ).

The location of each radio-tagged trout was determined weekly from 7 July 2005 to 13 October 2005. The large trout were detected within the river for periods ranging from 5 to 13 weeks (Table 1). RT3, RT5, and RT 7 were detected over a period of 13 weeks, until 29 September. After this they were no longer detected, and the tag batteries had likely expired. RT6 was captured by an angler and its tag returned to us; this fish was not observed in the river after week seven. Six large trout went unaccounted for at some point between weeks six and 13. The small trout were detected for periods ranging from 5 
to 10 weeks, and eight out of the ten tagged trout were recorded over the entire 10-week duration of the study. RT11 and RT14 were captured by anglers and their tags returned to us; these fish were not observed in the river after weeks five and eight, respectively. We assumed that a given fish was still alive and actively swimming during a week in which upstream movement was observed. Eighteen of twenty fish showed upstream movement (greater than the additive telemetry error of the previous and current week) on at least one tracking date (Table 1), with the last upstream movement occurring between two and 12 weeks after release. RT14 and RT15 showed only downstream or no movement, but RT14 was captured by anglers after 7 weeks in the river, indicating that it survived 7 weeks in spite of showing no upstream movement during tracking.

Large trout dispersed both upstream and down-

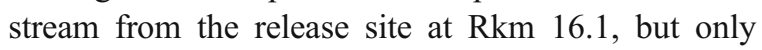
downstream from the release site at $\mathrm{Rkm} 12.9$ (Fig. 2). The large trout moved mainly during the first 4 weeks after their release. Eight of the trout moved 1.0-4.5 km downstream (Fig. 3a). RT10 moved the farthest during this period, quickly moving downstream $4.5 \mathrm{~km}$, before moving downstream another $0.5 \mathrm{~km}$. This fish moved upstream in the sixth week after release, then stayed in the same location for the next 4 weeks (Fig. 3a). While most of the others moved within 1.0-2.5 km downstream during this period, two trout (RT5 and RT6) stayed near their release sites for periods of 7 and 12 weeks respectively (Fig. 3a). Both these fish were apparently alive, since RT 5 moved upstream during the last week it was detected, and RT6 was captured by an angler. After the first 2 weeks, nine of the ten large trout moved little from one reach in the river, but all showed some upstream movement indicating that they were alive. In contrast, RT2 moved from a position $1.0 \mathrm{~km}$ downstream of the release site to a position $3.5 \mathrm{~km}$ downstream from the release site between the fifth and sixth week after its release (Fig. 2), and another $4.0 \mathrm{~km}$ downstream the following week (Figs. 2, 3a).

Small trout dispersed both upstream and downstream from both release sites (Fig. 2). They dispersed over a reach $1 \mathrm{~km}$ upstream and downstream of the release site during the first week (Fig. 3b). Eight of the small trout moved very little over the following eight weeks, although two fish were captured by anglers, and all but one of the remaining fish showed small upstream movements during this period, indicating that they were alive. In contrast to the other small trout, RT16 moved $2.0 \mathrm{~km}$ upstream between the fourth and seventh weeks, and RT12 moved the same distance downstream during the fifth and seventh weeks.

The median distances moved by the fish showed little relationship to mean water discharge rates (Fig. 4). The median movement of large trout was $1.1 \mathrm{~km}$ downstream during the large discharge rate of $40 \mathrm{~m}^{3} \mathrm{~s}^{-1}$ during the first week after release. However, the distance moved by large trout during the second week was less than in the first, despite the rate of discharge being slightly higher, at $43 \mathrm{~m}^{3} \mathrm{~s}^{-1}$. Furthermore, the majority of large and small trout moved little during subsequent weeks despite the discharge rate varying intermittently from 12 to 37 $\mathrm{m}^{3} \mathrm{~s}^{-1}$.

Habitat types (pools, runs, rapids) used by trout did not change markedly between base flow and pulse flow conditions. The movement of habitat boundaries was less than the transmitter location error. The large trout spent most of their time in runs (41\%), followed by pools (30\%) and rapids (29\%) during the 12 weeks that they were located within the river. The small trout were located in runs most often (42\%), followed by rapids $(30 \%)$ and pools $(28 \%)$ during the 9 weeks that they were located within the river. Both large (56\%) and small (51\%) trout tended to inhabit the main channel slightly more often than in the river margins over the two periods, although no clear pattern of preference emerged.

No significant relationships were found between weekly trout movement and the 11 potential predictive variables in the mixed model analysis of the ranked movement data (Table 2), although the model fit was adequate (convergence criteria were met; covariance parameter estimate for compound symmetry (subject $=$ fish-id(size)): $\operatorname{Pr} Z=0.9889$, residual: $\operatorname{Pr}$ $\mathrm{Z}<0.0001$; fit statistics: -2 res $\log$ likelihood= 1321.3, $\mathrm{AIC}=1325.3$; null model likelihood ratio test: $\left.\mathrm{df}=1, \chi^{2}=0.00, \operatorname{Pr}>\chi^{2}=0.9888\right)$.

\section{Discussion}

The hatchery rainbow trout in this study did not appear to be displaced downstream by the pulsed flow 
regime of the South Fork American River in the summer of 2005, in spite of over 20-fold daily flow fluctuations, or if fish were displaced they were able to regain their position prior to the next tracking event. Weekly movements of trout, either upstream or downstream, did not appear to be affected by the various metrics for flow and habitat we used in our model, nor did fish size appear to be a significant factor. Our results are similar to those of Gido et al. (2000) in which most adult rainbow trout were able to maintain position in the San Juan River during a reservoir discharge. Likewise, Klimley et al. (2005) found that radio-tagged adult rainbow trout and brown trout (Salmo trutta) were not displaced downstream by a one-day pulsed flow release in Silver Creek, a tributary of the South Fork American River, that experienced a greater than 35 -fold increase in flow. Salamunovich (2003) found little change in the observed species, number and sizes of fish before and after recreational pulsed flows in the Rock Creek and Cresta reaches of the North Fork Feather River. However, since observations were made on unmarked fish, via snorkel surveys, it is possible that fish were displaced downstream but were replaced by similar fish displaced from further upstream.

There were six large trout that went unaccounted for after the 6th to 13th week of the study. They may have been eaten by predators such as river otters, or caught by anglers who did not return the tags; anglers may have been more likely to release the smaller trout after capture. The large trout began to go missing around the same time that known angler captures occurred (5-8 weeks after release). It is possible that the large fish moved either upstream or downstream

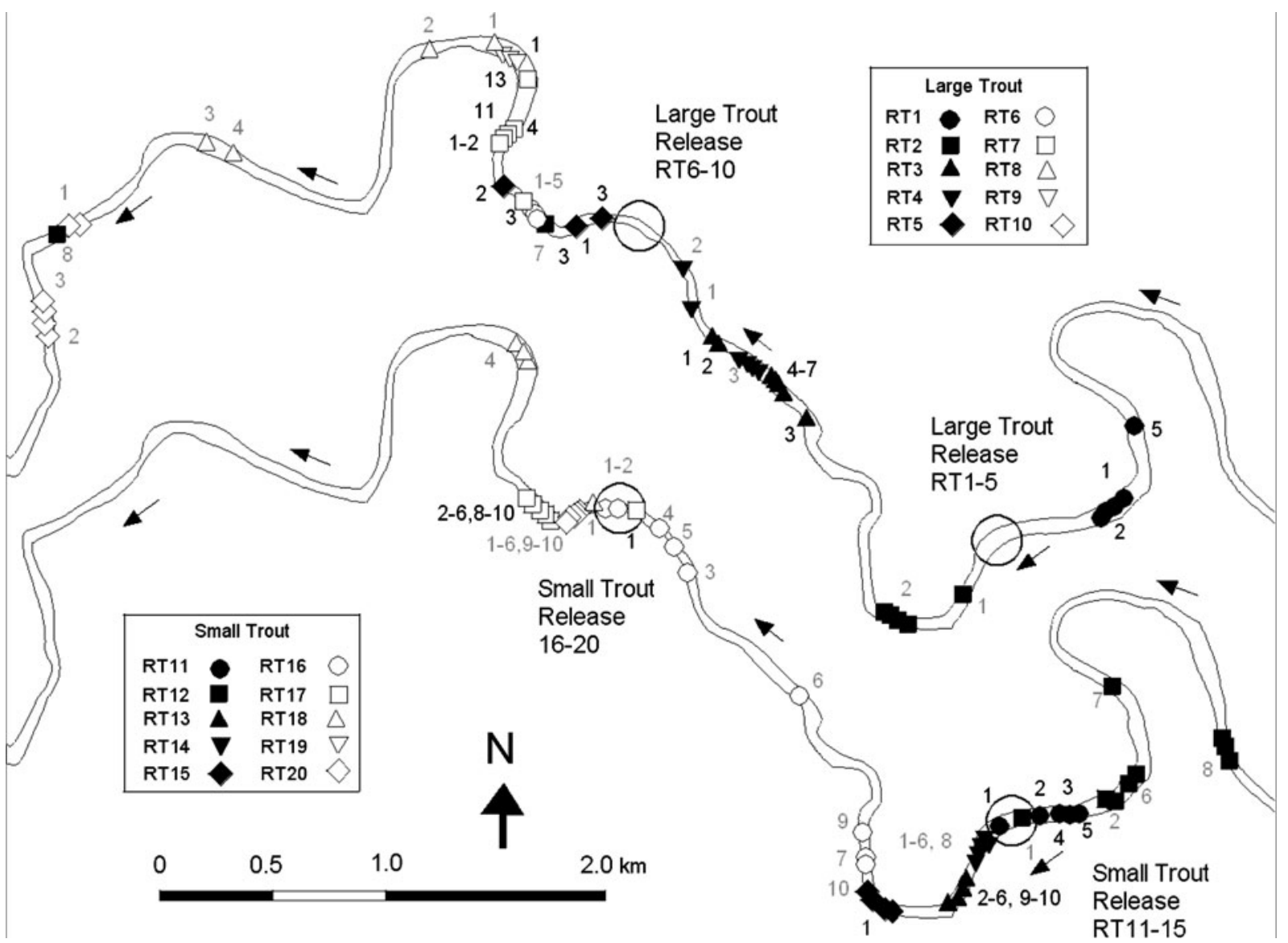

Fig. 2 Maps of the South Fork American River showing the release locations of the ten large rainbow trout (upper map) and ten small rainbow trout (lower map). Large trout were released on 7 July 2005, and small trout were released on 12 August
2005. The locations of individual fish in subsequent weeks are indicated with symbols, while the associated numbers indicate the week in which the fish was at a particular location. Fish ID codes correspond to the fish listed in Table 1 
Fig. 3 Distance from release site plotted for a large and $\mathbf{b}$ small rainbow trout released in the South Fork American River and tracked for periods of 13 and 9 weeks, respectively, while subjected to pulsed releases of water from Chili Bar Dam from 7 July to 29 September 2005. Trout released at the upstream site are indicated by black symbols, while trout released at the lower site are indicated by white symbols. Fish ID codes correspond to the fish listed in Table 1
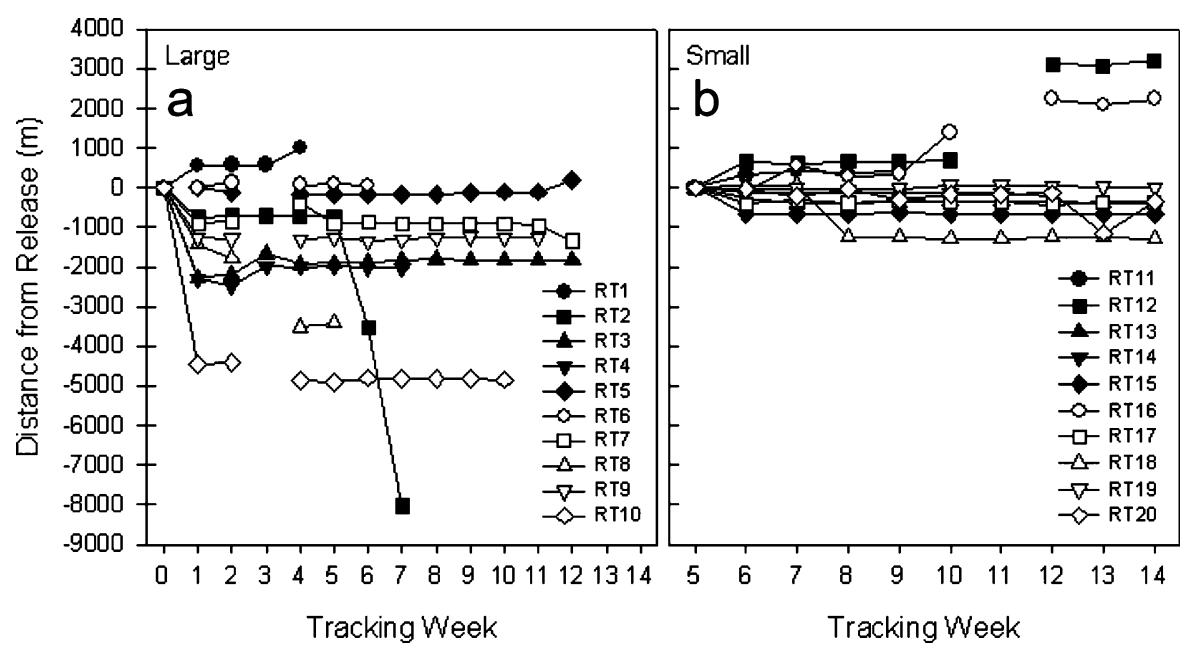

out of the study area. We did not use fixed antenna stations at the boundaries of our study area due to the very high levels of public foot and boat traffic, and consequent concerns for damage to or theft of unattended equipment. Fixed antennas would have permitted the detection of fish that left the study area. However, every fish that eventually went unaccounted for had shown both upstream or downstream movement in previous weeks of tracking (Table 1), and would have experienced a minimum of over 40 pulses before disappearing, indicating that they were not being steadily washed further and further downstream with successive pulsed flow releases. Our study would have been improved by having a larger starting sample size, in order to compensate for losses to angling and natural predation, and to provide a greater chance of observing all the possible variation that exists in movement.

Given the repeated pulsed flows occurring in the study area both day and night, it is not possible to determine what distribution and amount of movement these trout would have displayed in the absence of pulsed flows. This is a limitation of studying a reach where frequent pulsed flows are both mandated for recreation, and permitted for hydropower generation and flood control. In order to address this limitation
Fig. 4 Movement (median \pm 75th semi-quartile percentile) of trout and river discharge (mean \pm SE) during radio tracking studies in the American River. The large trout were released 5 weeks before the small trout. During tracks for week 13 and 14 none of the large radio-tagged trout were detected, presumably due to tag-battery senescence

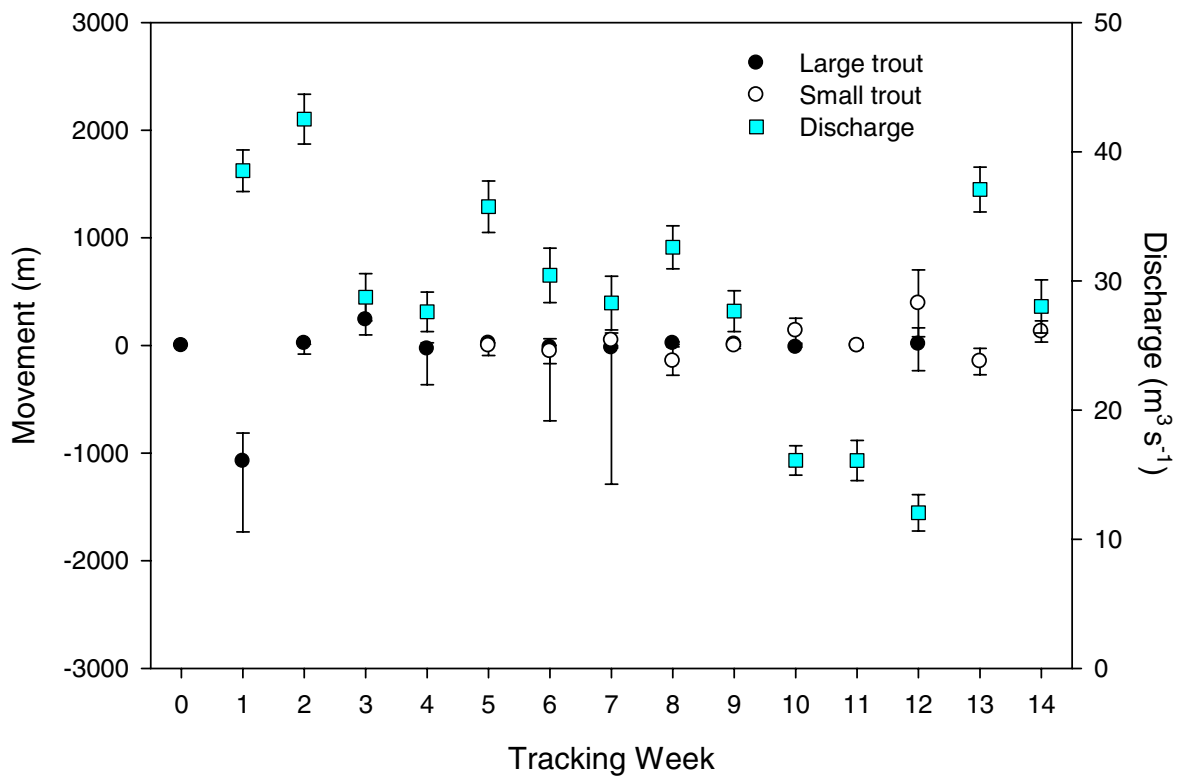


we conducted a separate study of a single-day pulse in a system where flows are rarely pulsed (Klimley et al. 2005). All the radio-tagged trout stayed within the $500-\mathrm{m}$ study reach during a 35-fold increase in flow, and there was no pattern of upstream or downstream movement.

Radio-tracking studies of rainbow trout, brown trout, bulltrout (Salvelinus confluentus), and cutthroat trout (Oncorhynchus clarki) under natural flow regimes are consistent in their findings that individual trout tend to remain in a small home area, generally $<1 \mathrm{~km}$, during non-spawning periods (Clapp et al. 1990; Young 1996, 1998; Knouft and Spotila 2002; Ovidio et al. 2002; Schrank et al. 2003; Aarestrup et al. 2005; Popoff and Neumann 2005; Hojesjo et al. 2007), but that they may move longer distances (e.g., 3-63 km) during migrations to spawning habitat (Bailey et al. 1978; Meyers et al. 1992; Brown and Mackay 1995; Swanberg 1997; Ovidio et al. 1998; Burrell et al. 2000; Hilderbrand and Kershner 2000; Meka et al. 2003; Arnekleiv and Roenning 2004; Bahr and Shrimpton 2004; Bettinger and Bettoli 2004; Muhlfeld and Marotz 2005; Venman and Dedual 2005). In the South Fork American River rainbow trout would be expected to spawn in spring, as high winter flows recede. Because our study was conducted in summer, well after the spawning period, we expected the trout to remain near their release locations unless they were affected by pulsed flows. The majority (17/20) of the trout in this study stayed in a small home area throughout the time they were observed, following an initial movement upstream or downstream directly after release, consistent with the behavior of trout in a non-pulsed system. Notably, three of the four large trout that disappeared part way through the study had maintained their position along the river for over a month prior to their disappearance.

The largest upstream movements of trout were accomplished during weeks of lower pulsed flows (weeks 11 and 12), which may indicate that fish may move upstream more readily when pulsed flow peaks are less extreme, and that high pulsed flows may limit the degree to which trout will move upstream. In a related laboratory study using a longitudinal flume juvenile rainbow trout (mean $\mathrm{SL}=5.0 \mathrm{~cm} \pm 0.2 \mathrm{SE}$; mean wet weight $=2.6 \mathrm{~g} \pm 0.4 \mathrm{SE}$ ) showed no significant net movement, upstream or downstream (longitudinal displacement) from their mid-flume starting point, and were capable of maintaining swimming speed and position during short flow pulses up to $0.46 \mathrm{~ms}^{-1}$ velocity (Klimley et al. 2005).

The tendency of trout in this study to stay in the main channel, as opposed to the river margins may be related to feeding behavior, as food may be more abundant in the main channel where a greater volume of water (and drifting food) would pass by a fish swimming to maintain position in the current. The assessment of swimming speed was outside the scope of the current study, but given the high potential for the influence of food supplies and energetic constraints on the movement of trout in response to pulsed flow releases, we conducted a companion study of the energetic output of trout during pulsed

Table 2 Repeated-measures analysis of variance for the ranks of weekly distance moved (m) by 15 radio-tracked rainbow trout, with fish as subjects, repeated measures over time, and 11 fixed main effects $(n=136)$

\begin{tabular}{|c|c|c|c|c|c|}
\hline Variables & Units & Class levels & $\mathrm{DF}$ & $\mathrm{F}$ & $\mathrm{P}$ \\
\hline Size & & 2 (large, small) & 1 & 0.01 & 0.9289 \\
\hline Weight & $\mathrm{g}$ & & 1 & 0.02 & 0.8944 \\
\hline Health index & Score from 11 to 55 & & 1 & 0.00 & 0.9907 \\
\hline Release location & & $2(\mathrm{Rkm} \mathrm{16.1,Rkm} \mathrm{12.9)}$ & 1 & 0.22 & 0.6535 \\
\hline Week & & 12 (week 1-12) & 11 & 0.99 & 0.4581 \\
\hline Habitat type & & 3 (rapid, run, pool) & 2 & 1.57 & 0.2166 \\
\hline Lateral river location & & 2 (main channel, margin) & 1 & 1.85 & 0.1774 \\
\hline Mean weekly daytime peak flow & $\mathrm{m}^{3} \mathrm{~s}^{-1}$ & & 1 & 1.74 & 0.1903 \\
\hline Mean weekly nighttime peak flow & $\mathrm{m}^{3} \mathrm{~s}^{-1}$ & & 1 & 1.82 & 0.1807 \\
\hline Mean weekly flow & $\mathrm{m}^{3} \mathrm{~s}^{-1}$ & & 1 & 2.60 & 0.1096 \\
\hline Weekly flow range & $\mathrm{m}^{3} \mathrm{~s}^{-1}$ & & 1 & 0.03 & 0.8554 \\
\hline
\end{tabular}

$D F$ degrees of freedom, $F$ variance ratio, $P$ probability $(\alpha \leq 0.05)$ 
flow events, through the use of implanted electromyogram radio transmitters (Klimley et al. 2007).

The overall distribution of large trout in our study is similar to that observed for adult Sacramento sucker in the Mokelumne River (Jeffres et al. 2006) in which most fish moved relatively short distances upstream or downstream from the release site in response to pulsed flows, but a few individuals moved large distances downstream. Initially after their release the large trout in our study moved downstream but in subsequent weeks they tended to remain in approximately the same location. The smaller trout did not show this same initial downstream displacement. The larger fish would have had higher caloric requirements relative to the smaller trout. If the larger trout were unable to find habitat with an adequate food supply they may have traveled in search of areas with greater food abundance, with downstream movement being less costly than upstream, thus spacing themselves out relative to the locally available food supply. The study reach had very few large rainbow trout (SMUD and PGE 2005), suggesting that it may not be suitable habitat, potentially due to the cumulative effects of repeated pulsed releases. However, we would not expect the habitat upstream or downstream of our study reach to have better habitat, since the flow regime is the same, and water temperatures downstream tended to increase above the optimal rearing range.

Our results suggest that the majority of hatchery rainbow trout released into the South Fork American River will not be washed downstream by repeated pulsed flows, and that most fish will remain in a home area within $3 \mathrm{~km}$ of their release site for several months, similar to trout in un-pulsed systems, unless captured by anglers or predators. We caution, however, that the ability of adult fish to maintain their position in the river does not necessarily imply that juvenile fish would have the same capability. Furthermore, the ability of trout to complete their life cycle, particularly spawning, egg incubation, and juvenile rearing, under the influence of repeated pulsed flows, was outside the scope of this study.

Acknowledgements This study was funded by the Public Interest Energy Research (PIER) Program of the California Energy Commission through the Pulsed Flow Program of the Center of Aquatic Biology and Aquaculture of the University of California, Davis. We also acknowledge support from the Division of Water Rights of the State Water Resources Control
Board. Dennis Redfern and Frank Harris from the American River Trout Hatchery supplied hatchery-raised trout. William Cox from the Fish Health Laboratory at the Department of Fish and Game provided guidance in medicating captive fish. Kyle Murphy from the Department of Fish and Game facilitated the return of recovered tags. Eric Miller, Jeff Parker and James Underhill returned radio tags from fish angled on the South Fork. We are grateful for thoughtful comments on the manuscript from several anonymous reviewers.

Open Access This article is distributed under the terms of the Creative Commons Attribution Noncommercial License which permits any noncommercial use, distribution, and reproduction in any medium, provided the original author(s) and source are credited.

\section{References}

Aarestrup K, Jepsen N, Koed A, Pedersen S (2005) Movement and mortality of stocked brown trout in a stream. J Fish Biol 66(3):721-728

Arnekleiv JV, Roenning L (2004) Migratory patterns and return to the catch site of adult brown trout (Salmo trutta L.) in a regulated river. River Res Appl 20(8):929-942

Bahr MA, Shrimpton JM (2004) Spatial and quantitative patterns of movement in large bull trout (Salvelinus confluentus) from a watershed in north-western British Columbia, Canada, are due to habitat selection and not differences in life history. Ecol Freshw Fish 13(4):294-304

Bailey R, Patula D, Green M, Weeks R, Long F (1978) Migratory behavior of Lahontan cutthroat trout (Salmo clarki henshawi) utilizing radiotelemetry. Cal Neva Wildlife 127-136

Beschta RL, Bilby, RE, Brown GW, Holtby LB, Hofstra TD (1987) Chapter 6: stream temperature and aquatic habitat. In: Salo, EO, Cundy TW (eds) Streamside management: forestry and fishery interactions. University of Washington, Institute of Forest Resources. Contribution No. 57. pp 191-232

Bettinger JM, Bettoli PW (2004) Seasonal movement of brown trout in the Clinch River, Tennessee. North Am J Fish Manage 24(4):1480-1485

Bradford MJ, Taylor GC, Allen JA, Higgins PS (1995) An experimental study of the stranding of juvenile coho salmon and rainbow trout during rapid flow decreases under winter conditions. North Am J Fish Manage 15:473-479

Brown RS, Mackay WC (1995) Spawning ecology of cutthroat trout (Oncorhynchus clarki) in the Ram River, Alberta. Can J Fish Aquat Sci 52(5):983-992

Bunt CM, Cooke SJ, Katopodis C, McKinley RS (1999) Movement and summer habitat of brown trout (Salmo trutta) below a pulsed discharge hydroelectric generating station. Regul River: Res Manage 15:395-403

Burrell KH, Isely JJ, Bunnell DB Jr, Van Lear DH, Dolloff CA (2000) Seasonal movement of brown trout in a southern Appalachian river. Trans Am Fish Soc 129 (6):1373-1379

Clapp DF, Clark RD, Diana JS (1990) Range, activity, and habitat of large, free-ranging brown trout in a Michigan stream. Trans Am Fish Soc 119(6):1022-1034 
Cooke SJ, Hinch SG, Farrell AP, Patterson DA, MillerSaunders K, Welch DW, Donaldson MR, Hanson KC, Crossin GT, Mathes MT, Lotto AG, Hruska KA, Olsson IC, Wagner GN, Thomson R, Hourston R, English KK, Larsson S, Shrimpton JM, Van der Kraak G (2008) Developing a mechanistic understanding of fish migrations by linking telemetry with physiology, behavior, genomics and experimental biology: an interdisciplinary case study on adult Fraser River sockeye salmon. Fisheries 33(7):321-338

Crisp DT (1991) Stream channel experiments on downstream movement of recently emerged trout, Salmo trutta L. and salmon, S. salar L.-Effects of developmental stage and day and night on dispersal. J Fish Biol 39:371-381

Crisp DT, Hurley MA (1991) Stream channel experiments on downstream movement of recently emerged trout, Salmo trutta L. and salmon, Salmo salar L.-1. Effect of four different water velocity treatments upon dispersal rate. J Fish Biol 39:347-361

Erman DC, Leidy GR (1975) Downstream movement of rainbow trout fry in a tributary of Sagehen Creek, under permanent and intermittent flow. Trans Am Fish Soc $104: 467-473$

FERC (Federal Energy Regulatory Commission) (2008) Final environmental impact statement for hydropower license. Upper American River Hydroelectric Project, FERC Project No. 2101-084, California, Chili Bar Hydroelectric Project, FERC Project No. 2155-024, California. FERC/ FEIS-0216F, $692 \mathrm{p}$

Gido KB, Larson RD, Ahlm LA (2000) Stream-channel position of adult rainbow trout downstream of Navajo Reservoir, New Mexico, following changes in reservoir release. North Am J Fish Manage 20:250-258

Heggenes J, Traaen T (1988) Downstream migration and critical water velocities in stream channels for fry of four salmonid species. J Fish Biol 32:17-727

Heggenes J, Omholt PK, Kristiansen JR, Sageie J, Økland F, Dokk JG, Beere MC (2007) Movements by wild brown trout in a boreal river: response to habitat and flow contrasts. Fish Manage Ecol 14:333-342

Hilderbrand RH, Kershner JL (2000) Movement patterns of stream-resident cutthroat trout in Beaver Creek, IdahoUtah. Trans Am Fish Soc 129(5):1160-1170

Hojesjo J, Okland F, Sundstrom LF, Pettersson J, Johnsson JI (2007) Movement and home range in relation to dominance; a telemetry study on brown trout Salmo trutta. J Fish Biol 70(1):257-268

Hunter MA (1992) Hydropower flow fluctuations and salmonids: a review of the biological effects, mechanical causes and options for mitigation. Washington Department of Fisheries Technical Report 119

Hvidsten NA (1985) Mortality of pre-smolt Atlantic salmon, Salmo salar L., and brown trout, S. trutta L., caused by fluctuating water levels in the regulated River Nidelva, central Norway. J Fish Biol 42:1922-1927

Jeffres CA, Klimley AP, Merz JE, Cech JJ Jr (2006) Movement of Sacramento sucker, Catostomus occidentalis, and hitch, Lavinia exilicauda, during a spring release of water from Camanche Dam in the Mokelume River, California. Environ Biol Fish 75:365-373
Jepsen N, Koed A, Thorstad EB, Baras E (2002) Surgical implantation of telemetry transmitters in fish: how much have we learned? Hydrobiology 483:239-248

Klimley AP, Cech JJ Jr, Thompson LC, Hamilton S, Chun SN (2005) Experimental and field studies to assess pulsed, water-flow impacts on the behavior and distribution of fishes in California rivers, annual report, 2004-05. Prepared for the PIER Program Area, California Energy Commission. 107 p. http://www.energy.ca.gov/publications/displayOneReport. php?pubNum=CEC-500-2005-172

Klimley AP, Cech JJ Jr, Thompson LC, Hamilton S (2007) Experimental and field studies to assess pulsed, water flow impacts on the behavior and distribution of fishes in the South Fork of the American River, II (Second Year). University of California, Davis, for the California Energy Commission, PIER Energy-Related Environmental Research. $85 \mathrm{p}$

Knouft JH, Spotila JR (2002) Assessment of movements of resident stream brown trout, Salmo trutta L., among contiguous sections of stream. Ecol Freshw Fish 11 (2):85-92

Maciolek JA, Needham PR (1952) Ecological effects of winter conditions on trout and trout foods in Convict Creek, California, 1951. Trans Am Fish Soc 81:202-217

McCrimmon HR (1954) Stream studies on planted Atlantic salmon. J Fish Res Board Can 11:362-403

Meka JM, Knudsen EE, Douglas DC, Benter RB (2003) Variable migratory patterns of different adult rainbow trout life history types in a southwest Alaska watershed. Trans Am Fish Soc 132(4):717-732

Meyers LS, Thuemler TF, Kornely GW (1992) Seasonal movements of brown trout in northeast Wisconsin. $\mathrm{N}$ Am J Fish Manage 12(3):433-441

Moyle PB (2002) Inland fishes of California. University of California Press, Berkeley

Muhlfeld CC, Marotz B (2005) Seasonal movement and habitat use by subadult bull trout in the Upper Flathead River system, Montana. N Am J Fish Manage 25(3):797-810

Ottaway EM, Clarke A (1981) A preliminary investigation into the vulnerability of young trout (Salmo trutta L.) and Atlantic salmon (S. salar L.) to downstream displacement by high water velocities. J Fish Biol 19:135-145

Ottaway EM, Forrest DR (1983) The influence of water velocity on the downstream movements of alevins and fry of brown trout, Salmo trutta L. J Fish Biol 23:221-436

Ovidio M, Baras E, Goffaux D, Birtles C, Philippart JC (1998) Environmental unpredictability rules the autumn migration of brown trout (Salmo trutta L.) in the Belgian Ardennes. Hydrobiologia 371-372(1-3):263-274

Ovidio M, Baras E, Goffaux D, Giroux F, Philippart J (2002) Seasonal variations of activity pattern of brown trout (Salmo trutta) in a small stream, as determined by radiotelemetry. Hydrobiologia 470(1-3):195-202

Peake S (1998) Sodium bicarbonate and clove oil as potential anesthetics for non-salmonid fishes. North Am J Fish Manage 18:919-924

Pearsons TN, Li HW, Lamberti GA (1992) Influence of habitat complexity on resistance to flooding and resilience of stream fish populations. Trans Am Fish Soc 121:427-436

PGE (Pacific Gas and Electric) (2005a) Flow and fluctuation in the reach downstream of Chili Bar Technical Report. Sacramento Municipal Utility District Upper American 
River Project (FERC Project No. 2101) and Pacific Gas and Electric Company Chili Bar Project (FERC Project No. 2155). May 2005, version 2. $294 \mathrm{p}$

PGE (Pacific Gas and Electric) (2005b) Water temperature technical report. Sacramento Municipal Utility District Upper American River Project (FERC Project No. 2101) and Pacific Gas and Electric Company Chili Bar Project (FERC Project No. 2155). May 2005, version 5. $243 \mathrm{p}$

Popoff ND, Neumann RM (2005) Range and movement of resident holdover and hatchery brown trout tagged with radio transmitters in the Farmington River, Connecticut. $\mathrm{N}$ Am J Fish Manage 25(2):413-422

Reiser DW, Wesche TA, Estes C (1989) Status of in stream flow legislation and practice in North America. Fisheries 14:22-29

Salamunovich T (2003) Rock Creek-Cresta (FERC No. 1962) recreation and pulse flow biological evaluation: stranding and displacement studies. Draft report of Thomas R. Payne and Associates, Arcata, CA to Pacific Gas and Electric Company, San Ramon, CA

Schrank AJ, Rahel FJ, Johnstone HC (2003) Evaluating laboratory-derived thermal criteria in the field: an example involving Bonneville cutthroat trout. Trans Am Fish Soc 132(1):100-109

Scruton DA, Pennell CJ, Robertson MJ, Ollerhead LMN, Clarke KD, Alfredsen K, Harby A, McKinley RS (2005) Seasonal response of juvenile Atlantic salmon to experimental hydropeaking power generation in Newfoundland, Canada. North Am J Fish Manage 25:964-974
SMUD and PGE (Sacramento Municipal Utility District and Pacific Gas and Electric Company) (2005) Sacramento Municipal Utility District's Upper American River Project (FERC Project No. 2101) and Pacific Gas and Electric Company's Chili Bar Project (FERC Project No. 2155). Stream fisheries technical report, January 2005, version 2. Prepared by Devine Tarbell and Associates, Inc., Sacramento, California and Stillwater Sciences, Davis, California

Swanberg TR (1997) Movements of and habitat use by fluvial bull trout in the Blackfoot River, Montana. Trans Am Fish Soc 126(5):735-746

Swanson C, Young PS, Cech JJ Jr (2004) Swimming in twovector flows: performance and behavior of juvenile Chinook salmon near a simulated screened water diversion. Trans Am Fish Soc 133:265-278

Venman MR, Dedual M (2005) Migratory behaviour of spawning rainbow trout (Oncorhynchus mykiss) in the Tongariro River, New Zealand, after habitat alteration. N Z J Mar Freshw Res 39(4):951-961

Webb PW (1971) The swimming energetics of trout. I. Thrust and power at cruising speeds. J Exp Biol 55:489-500

Young MK (1996) Summer movements and habitat use by Colorado River cutthroat trout (Oncorhynchus clarki pleuriticus) in small, montane streams. Can J Fish Aquat Sci 53(6):1403-1408

Young MK (1998) Absence of autumnal changes in habitat use and location of adult Colorado River cutthroat trout in a small stream. Trans Am Fish Soc 127(1):147-151 